\title{
The ectodomain of the Notch3 receptor accumulates within the cerebrovasculature of CADASIL patients
}

\author{
Anne Joutel, ${ }^{1,2}$ Fréderic Andreux, ${ }^{1}$ Swann Gaulis, ${ }^{1}$ Valérie Domenga, ${ }^{1}$ Michaelle Cecillon, ${ }^{1}$ \\ Nicole Battail, ${ }^{3}$ Nadia Piga, ${ }^{3}$ Françoise Chapon, ${ }^{4}$ Catherine Godfrain, ${ }^{5}$ \\ and Elisabeth Tournier-Lasserve $e^{1,2}$
}

${ }^{1}$ INSERM U25, Faculté de Médecine Necker-Enfants Malades, Paris 75730, France

${ }^{2}$ Laboratoire de Cytogénétique, Hôpital Lariboisière, Paris 75010, France

${ }^{3}$ Département Recherche et Développement Immunoassays, bioMérieux, Chemin de l'Orme, Marcy L’Etoile 69280, France

${ }^{4}$ Laboratoire de Neuropathologie, Centre Hospitalier Régional et Universitaire de Caen, 14033 Caen Cedex, France

${ }^{5}$ Laboratoire de Neuropathologie, Clinique St-Luc, Brussels 1200, Belgium

Address correspondence to: Anne Joutel, INSERM U25, Faculté de Médecine Necker-Enfants Malades, 156 rue de Vaugirard, Paris 75730, France. Phone: 33-1-45-67-25-97; Fax: 33-1-40-56-01-07; E-mail: joutel@necker.fr.

Received for publication August 3, 1999, and accepted in revised form January 18, 2000.

\begin{abstract}
Mutations in Notch3 cause CADASIL (cerebral autosomal dominant adult onset arteriopathy), which leads to stroke and dementia in humans. CADASIL arteriopathy is characterized by major alterations of vascular smooth muscle cells and the presence of specific granular osmiophilic deposits. Patients carry highly stereotyped mutations that lead to an odd number of cysteine residues within EGF-like repeats of the Notch 3 receptor extracellular domain. Such mutations may alter the processing or the trafficking of this receptor, or may favor its oligomerization. In this study, we examined the Notch3 expression pattern in normal tissues and investigated the consequences of mutations on Notch3 expression in transfected cells and CADASIL brains. In normal tissues, Notch3 expression is restricted to vascular smooth muscle cells. Notch3 undergoes a proteolytic cleavage leading to a $210-\mathrm{kDa}$ extracellular fragment and a 97-kDa intracellular fragment. In CADASIL brains, we found evidence of a dramatic and selective accumulation of the $210-\mathrm{kDa}$ Notch 3 cleavage product. Notch 3 accumulates at the cytoplasmic membrane of vascular smooth muscle cells, in close vicinity to but not within the granular osmiophilic material. These results strongly suggest that CADASIL mutations specifically impair the clearance of the Notch3 ectodomain, but not the cytosolic domain, from the cell surface.

J. Clin. Invest. 105:597-605 (2000).
\end{abstract}

\section{Introduction}

We recently established that mutations in Notch3 cause CADASIL, a cerebral autosomal dominant adult onset arteriopathy which leads to stroke and dementia in humans (1-4). This condition is underlaid by an arteriopathy that affects mainly the small cerebral arteries. It is characterized by prominent alterations of vascular smooth muscle cells that eventually disappear, and the presence, on ultrastructural analysis, of rounded granular osmiophilic material located in close vicinity to the basement membrane of these cells (5-7). So far the nature of this material remains unknown.

Notch3 belongs to the family of highly conserved Notch/LIN-12 receptors, which includes 4 members in vertebrates (8). It encodes a protein of 2,321 amino acids that includes all canonical Notch motifs, i.e., an extracellular domain containing 34 tandem EGF-like repeats, 3 cysteine-rich Notch/LIN-12 repeats, a single transmembrane domain, and an intracellular domain containing 6 tandem ankyrin repeats. All CADASIL mutations lead to the addition or the loss of a cysteine residue within a given EGF domain, and therefore to an odd number of cysteine residues, because an EGF domain contains an invariant number of 6 cysteine residues (9).
Such mutations might alter the overall conformation of the Notch3 receptor, or prevent its processing and targeting to the cell surface. Indeed, it is now established that Notch1 and Notch2 receptors are constitutively cleaved between the LIN-12 repeats and the transmembrane domain, in the trans-Golgi network. The resulting cleavage products, which include the extracellular and the intracellular domains, are associated and carried to the cell surface to form a heterodimeric receptor $(10,11)$. Alternatively, these mutations might favor abnormal oligomerization of the Notch3 protein.

Examination of the Notch 3 expression pattern has been conducted primarily during development in rodents. Notch3 is expressed during gastrulation and in the developing central nervous system; expression appears to be strongly downregulated in the postnatal period (12-14). Northern blot analysis indicates that Notch3 is ubiquitously expressed in human adult tissues, but is barely detectable in the brain (A. Joutel, unpublished results).

In this study, we examined the Notch 3 expression pattern in various human adult tissues from control individuals using in situ hybridization and immunohistochemistry, and found that it was restricted to vascular 
smooth muscle cells. We then investigated the consequences of mutations on Notch 3 expression in transfected cells and in CADASIL brains by immunohistochemical and immunoblot analyses. In CADASIL patients, there was a dramatic accumulation, within the brain vasculature, of the $210-\mathrm{kDa}$ Notch3 cleavage product including the extracellular domain. Immunoelectron microscopy indicated that Notch3 accumulated at the cytoplasmic membrane of vascular smooth muscle cells, within highly restricted areas located in close vicinity to the granular osmiophilic material.

\section{Methods}

Control individuals. Samples of various parenchyma were obtained at autopsy ( 10 individuals aged 3 months to 84 years) or at surgery ( 3 individuals, $36-53$ years old). Tissues were fixed in $10 \%$ neutral-buffered formalin fixative and embedded in paraffin. Tissues from 3 individuals were frozen and stored at $-80^{\circ} \mathrm{C}$.

CADASIL patients. Brain tissue was obtained at autopsy (8 individuals, 49-66 years old) or at surgery ( 1 individual, 54 years old). All these patients belong to a CADASIL pedigree in which a pathogenic mutation has been identified: $\mathrm{R}_{153} \mathrm{C}\left(\mathrm{n}^{\circ} 1\right.$ and $\left.\mathrm{n}^{\circ} 2\right), \mathrm{R}_{169} \mathrm{C}\left(\mathrm{n}^{\circ} 3\right)$, $\mathrm{R}_{90} \mathrm{C}\left(\mathrm{n}^{\circ} 4\right), \mathrm{R}_{182} \mathrm{C}\left(\mathrm{n}^{\circ} 5\right), \mathrm{R}_{141} \mathrm{C}\left(\mathrm{n}^{\circ} 6\right.$ and $\left.\mathrm{n}^{\circ} 9\right), \mathrm{R}_{110} \mathrm{C}$ $\left(\mathrm{n}^{\circ} 7\right)$, and deletion of 7 amino acids including $\mathrm{C}_{117}$ $\left(n^{\circ} 8\right)$ (ref. 9 and A. Joutel and E. Tournier-Lasserve, unpublished results). Brain fragments (patients 1-8) were fixed in $10 \%$ neutral-buffered formalin fixative for 48 hours to several years and then embedded in paraffin or frozen (patients 1,8 , and 9) and stored at $-80^{\circ} \mathrm{C}$.

In situ bybridization. Sense and antisense ${ }^{35}$ S-labeled RNA probes were synthesized from 2 human Notch 3 cDNAs. HN3X cNDA (nucleotides 3184-5490) encodes all or part of the last 8 EGF repeats and the 2 first ankyrin repeats; SHB1 cDNA (nucleotides 5851-7055) encodes all or part of the last 2 ankyrin repeats and the $\mathrm{COOH}$ terminal intracellular region; Notch3 nucleotide numbering is according to the European Molecular Biology Laboratory, U97669. In situ hybridization was performed on $7-\mu \mathrm{m}$ paraffin sections according to a previously published protocol (15). Three to 8 sections of each sample were examined with dark-field and bright-field illumination on a Leica DMR microscope.

Generation of antibodies that specifically recognize Notch3. Histidine-tagged fusion proteins corresponding to EGF repeats $17-21$ (amino acids 657-846) and the nonconserved intracellular epitope (amino acids 2117-2244) of the human Notch3 protein were prepared from Sf9 insect cells infected with recombinant baculoviruses. Fusion proteins were purified over $\mathrm{Ni}^{2+}$ agarose beads and then injected into rabbits for the production of polyclonal antibodies, and into mice for the production of monoclonal antibodies. Polyclonal sera and hybridoma supernatants were screened on cells transfected with the full-length human Notch 3 cDNA by Western blot and immunofluorescence. Positive antibodies were further examined for their absence of cross-reactivity with Notch1 and Notch2 using transfected cells.
Immunohistochemistry. Immunohistochemistry was performed on $5-\mu \mathrm{m}$ paraffin sections. The following primary antibodies were used: anti-Notch3 extracellular domain (1E4 and 2E11 hybridoma supernatant, 1:5 dilution); anti-Notch3 intracellular domain (6A10 hybridoma supernatant, 1:2 dilution); anti-smooth muscle $\alpha$-actin (1A4; DAKO A/S, Glostrup, Denmark) (1:100 dilution); anti-smooth muscle myosin heavy chain (hSM-V; Sigma, St. Louis, Missouri, USA) (1:1000 dilution); and anti-vascular endothelial cell antigen CD34 (QBEND10; Immunotech S.A., Marseilles, France) (1:50 dilution). Immunoreactivity was revealed with biotinylated horse anti-mouse antibody and avidin/biotin horseradish peroxidase complex (VECTASTAIN ABC-HRP kit, Vector Laboratories, Burlington, California, USA), and was developed with 3,3'-diaminobenzidine (DAB; Sigma-Aldrich Chemie, Steinheim, Germany). Sections were examined on a Leica DMR microscope.

Tissue extracts and Western blotting. Tissue was homogenized in a solution containing $10 \mathrm{mM}$ Tris-Cl, 150 $\mathrm{mM} \mathrm{NaCl}$, and protease inhibitors (Complete; Boehringer Mannheim, Mannheim, Germany). Whole lysate was prepared by further solubilization of the homogenate in $2 \times$ SDS-Laemmli buffer (4\% SDS, 317 mmol 2-mercaptoethanol $[\beta \mathrm{ME}])$. In some experiments, a centrifugation step performed at $16,000 \mathrm{~g}$ was added to allow crude separation of cytosolic proteins (supernatant) from noncytosolic proteins enriched in membrane proteins; the resulting pellet was resuspended in $8 \%$ sucrose, $100 \mathrm{mM} \mathrm{NaCl}$, and $30 \mathrm{mM}$ imidazole ( $\mathrm{pH}$ 6.8) with protease inhibitors. Proteins in each fraction were further solubilized in $2 \times$ SDSLaemmli buffer and then heated for 30 minutes at $45^{\circ} \mathrm{C}$. Samples adjusted to $1 \times$ SDS-Laemmli buffer were run on a $6 \%$ SDS-PAGE gel and were transferred onto nitrocellulose membranes. Immunodetection was performed by sequential incubations with anti-Notch3 antibody and horseradish peroxidase-conjugated goat anti-mouse antibody (Jackson ImmunoResearch Laboratories Inc., West Grove, Pennsylvania, USA) followed by enhanced chemiluminescence detection (ECL; Pierce Chemical Co., Rockford, Illinois, USA).

$R T-P C R$. Reverse-transcribed products prepared from brain total RNA were amplified using Notch3 primers derived from exons 30 and 33. PCR products were hybridized with an oligonucleotide probe derived from exon 30. Primers and oligonucleotide probes derived from the human porphobilinogen deaminase gene were used as controls. Scanned autoradiographs were quantitated with the public domain NIH Image program available at http://rsb.info.nih.gov/nih-image.

Electron microscopy. Electron microscopy was performed on tissue fixed in glutaraldehyde and embedded in Epon (Fluka Chemie, Buchs, Switzerland) according to standard procedures. Immunoelectron microscopy was performed on $7-\mu \mathrm{m}$ paraffin sections with the $1 \mathrm{E} 4$ hybridoma supernatant (1:2 dilution). Staining was done with a goat antimouse antibody linked to colloidal gold particles $(\sim 5 \mathrm{~nm})$ followed by silver enhancement (Amersham, Buckingshire, 

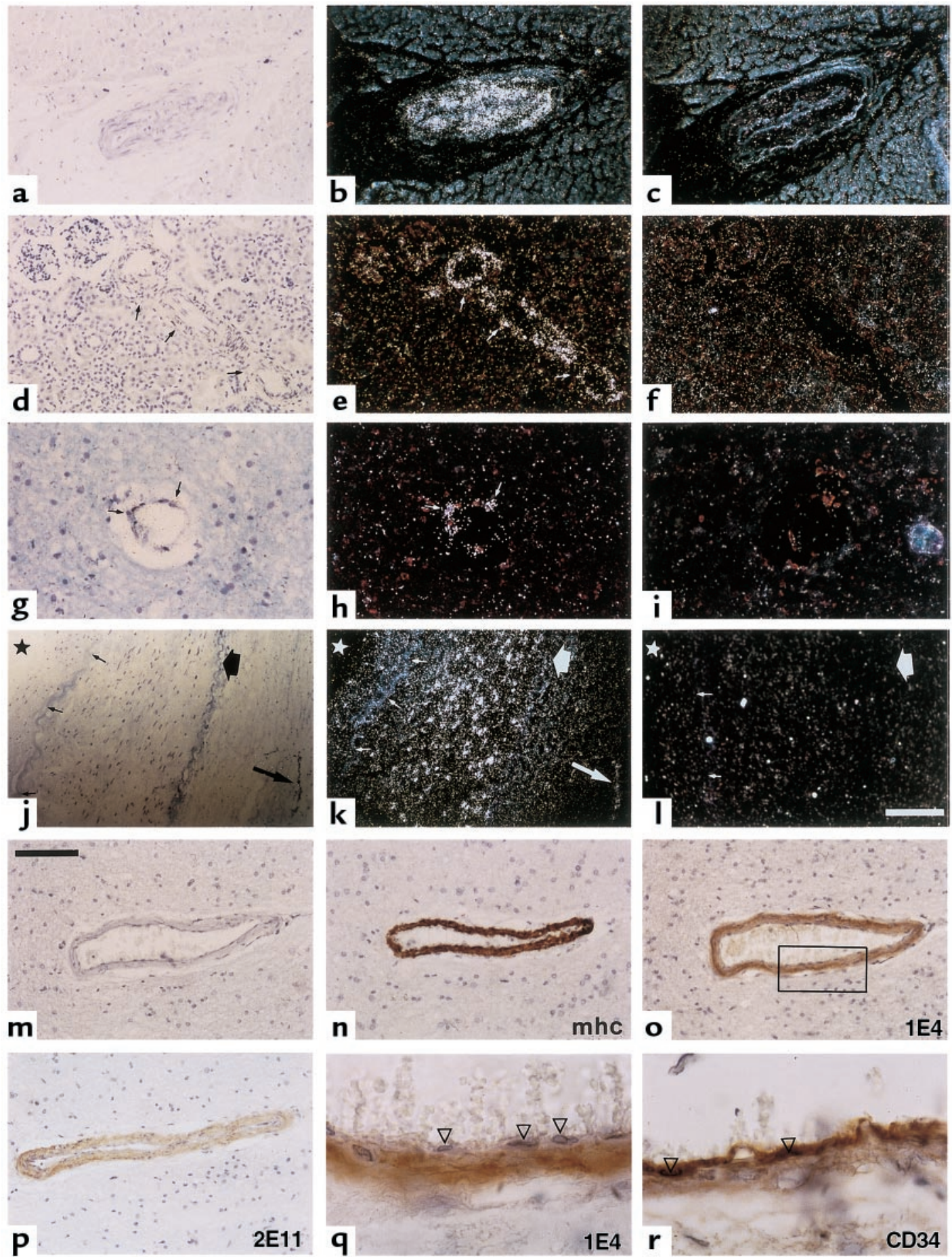

\section{Figure 1}

Notch3 expression is restricted to vascular smooth muscle cells in human adult tissues. Notch3 expression was examined on paraffin sections from control individuals by in situ hybridization (a-I) and immunohistochemistry $(\mathbf{m}-\mathbf{r})$. Sections of myocardium (a-c), kidney $(\mathbf{d}-\mathbf{f})$, brain white matter $(\mathbf{g}-\mathbf{i})$, and renal artery $(\mathbf{j}-\mathbf{I})$ were hybridized with Notch3 antisense riboprobe (b, e, h, and $\mathbf{k})$ and Notch 3 sense riboprobe (c, $\mathbf{f}, \mathbf{i}$, and I). Kidney sections were hybridized with the HN3X riboprobes; all other sections with the SHB1 riboprobes. Bright fields (a, d, $\mathbf{g}$, and $\mathbf{j}$ ) and corresponding dark-field micrographs are shown. Notch3 is detected exclusively in the vessels (arrows) within the various parenchyma $(\mathbf{a}-\mathbf{i})$, and primarily in the smooth muscle cell layer of the media or in vessels of the adventitia within the renal artery (j-I). Small arrows in $\mathbf{k}$ indicate the internal elastica lamina, the thick arrow shows the external elastica lamina, and the star marks the luminal side. The bar in I represents $125 \mu \mathrm{m}$ for $\mathbf{a}-\mathbf{c}, 100 \mu \mathrm{m}$ for $\mathbf{d}-\mathbf{f}, 50 \mu \mathrm{m}$ for $\mathbf{g}-\mathbf{i}$, and $200 \mu \mathrm{m}$ for j-I. (m-r) Adjacent paraffin sections of brain frontal lobe were immunostained with primary antibodies recognizing the smooth muscle myosin heavy chain $(\mathrm{mhc})(\mathbf{n})$, Notch3 extracellular epitopes $1 \mathrm{E} 4$ (o and $\mathbf{q})$ and 2E11 (p), and the vascular endothelial cell marker CD34 (r). In m, primary antibody was omitted. Anti-Notch3 antibodies exclusively immunostained the smooth muscle cells (o-q) but not the endothelial cells (arrowheads). Bar, $100 \mu \mathrm{m}$ for $\mathbf{m}-\mathbf{p}$ and $20 \mu \mathrm{m}$ for $\mathbf{q}$ and $\mathbf{r}$ (higher magnification of the boxed area of the vessel wall in $\mathbf{o})$. Counterstaining was with toluidine blue $(\mathbf{a}-\mathbf{I})$ and with hematoxylin ( $\mathbf{m}-\mathbf{r})$. 

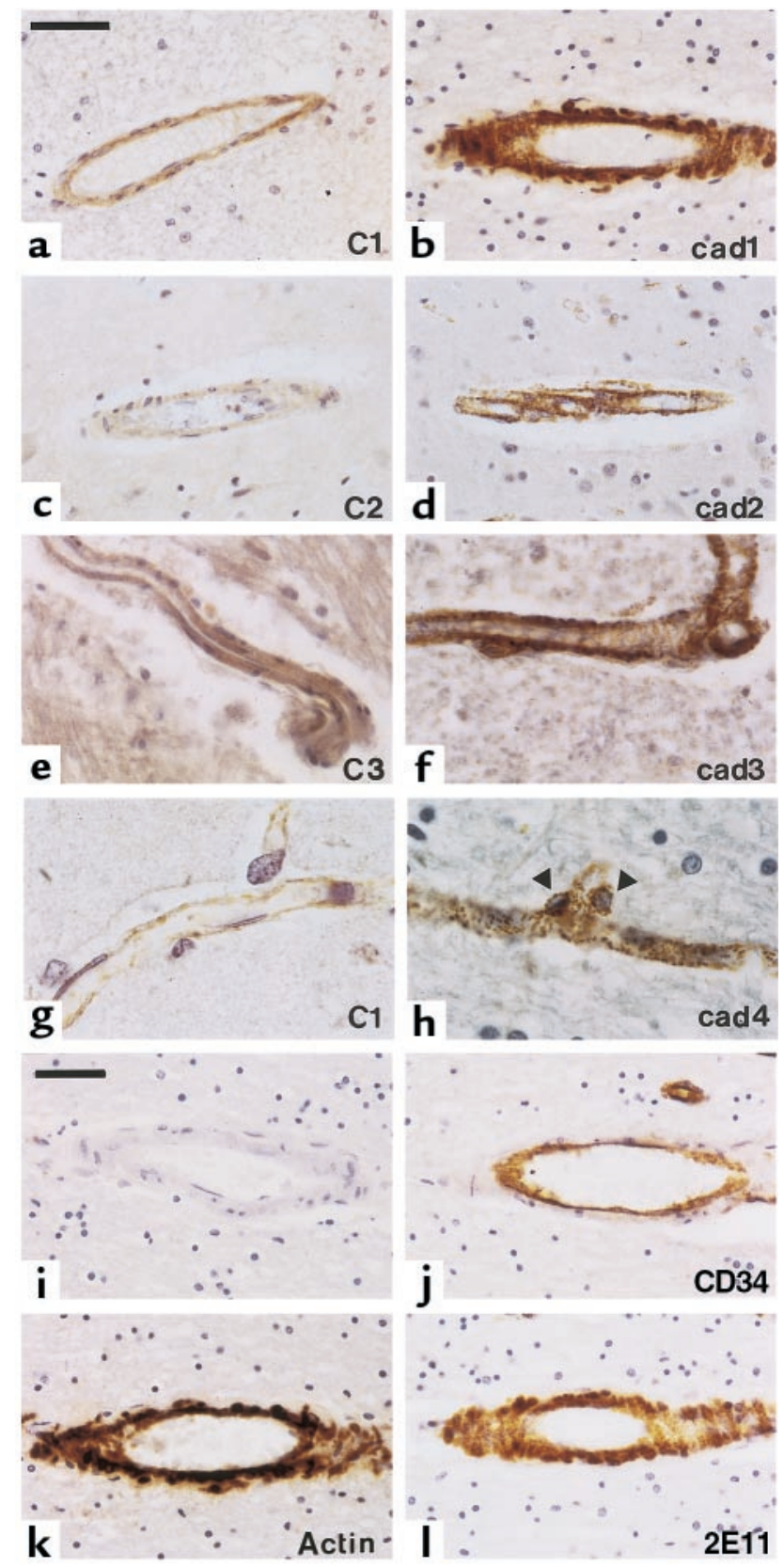

England). Procedures for immunoelectron microscopy were as described (16). Micrographs were recorded on a Phillips EM 201 electron microscope.

Cell culture, transfection, and extract preparation. A fulllength Notch 3 cDNA was assembled and cloned into the PSG5 expression vector (Stratagene, La Jolla, California, USA). Mutations $\mathrm{R}_{90} \mathrm{C}$ and $\mathrm{C}_{212} \mathrm{~S}$ were introduced using mutagenic oligonucleotides. 293T cells were cultured in 6-well plates and were transiently transfected by calcium phosphate precipitation. Cell extracts were prepared as described (11).

Cell surface biotinylation. Two days after transfection, cells were incubated with $2 \mathrm{mg} / \mathrm{mL}$ sulfo-NHS-biotin (Pierce Chemical Co.) as described (10). Cells were then washed and lysed in RIPA buffer and were incubated with streptavidin-agarose beads overnight at $4^{\circ} \mathrm{C}$. Bound proteins were eluted with $2 \times$ SDS-Laemmli
Figure 2

Intense and granular appearance of Notch3 immunoreactivity in CADASIL brains. (a-h) Paraffin sections from control (C1-C3; a, c, e, and $\mathbf{g}$ ) and CADASIL brains (cad1-cad $4 ; \mathbf{b}, \mathbf{d}, \mathbf{f}$, and $\mathbf{h}$ ) including sections from white matter ( $\mathbf{a}$ and $\mathbf{b})$, cortex $(\mathbf{c}, \mathbf{d}, \mathbf{g}$, and $\mathbf{h})$, and brainstem (e and f), were probed with the $1 \mathrm{E} 4$ anti-Notch3 antibody. The examples shown are from 3 control individuals and 4 CADASIL brains matched for formalin fixation conditions and duration: 48 hours for control 1 (a and $\mathbf{g}$ ) and CADASIL patient 1 (b); 0.5 months and 3 months for control 2 (c) and CADASIL patient 2 (d), respectively; 8 years for control 3 (e) and CADASIL patient $3(\mathbf{f})$, and 1 year for CADASIL patient $4(\mathbf{h})$. Notch3 immunoreactivity is much more intense within smooth muscle cells of vessels from CADASIL brains than in control brains (a-h, right column compared with left column) for all durations of fixation. Granular and intense Notch3 immunostaining is also obvious within pericytes of capillaries (arrows, nuclei of pericytes) (h). Identical observations were obtained in brains from other donors (4 CADASIL patients, 2 controls). Bar, $50 \mu \mathrm{m}$ for $\mathbf{a}-\mathbf{f}$ and $20 \mu \mathrm{m}$ for $\mathbf{g}$ and $\mathbf{h}$. (i-I) Adjacent paraffin sections from CADASIL brain (patient 1) were probed with the 2E11 anti-Notch3 antibody $(\mathbf{I})$, the anti-CD34 antibody (which is of the same isotype as the 1E4 and 2E11 antibodies) to identify the endothelial cells (j), the anti-smooth muscle $\alpha$-actin antibody (to identify smooth muscle cells) (k), or without primary antibody (i). Bar, $50 \mu \mathrm{m}$. Counterstaining was with hematoxylin.

buffer, after which they were heated at $100^{\circ} \mathrm{C}$ and subjected to $6 \%$ SDS-PAGE and immunoblotting with anti-Notch3 antibodies 5E1 and 5G7.

Immunoprecipitation. Two days after transfection, cells were lysed in $0.5 \%$ Triton X-100 buffer containing protease inhibitors. Immunoprecipitations were carried out with the BC2 and BC4 polyclonal anti-Notch3 antibodies and a preimmune rabbit serum.

\section{Results}

Notch 3 expression is restricted to vascular smooth muscle cells in buman adult tissues. We investigated the Notch3 expression pattern in a broad panel of human adult tissues from control individuals $(n=13)$, using both in situ hybridization $(n=7)$ and immunohistochemistry $(n=$ 10). To avoid cross-hybridization with Notch1, Notch2, and Notch 4 transcripts, we designed 2 sets of both sense and anti-sense riboprobes from regions of the Notch3 gene showing the lowest homology with these transcripts. Examination of sections of various parenchyma (Figure 1), including heart $(\mathrm{a}-\mathrm{c})$, kidney $(\mathrm{d}-\mathrm{f})$, brain $(\mathrm{g}-\mathrm{i})$, large artery $(j-1)$, skeletal muscle, lung, urinary bladder, and large intestine (data not shown) from at least 2 distinct individuals per tissue indicated that Notch3 expression is restricted to the vasculature. The 2 antisense Notch3 riboprobes showed the same hybridization pattern (data not shown).

Restriction of expression to the vasculature was confirmed by immunohistochemical analysis on paraffin sections with 2 anti-Notch 3 antibodies that we raised against the extracellular domain, 1E4 and 2E11. Notch3 expression was further restricted to the smooth muscle cell layer within the vessels (Figure 1, o-q). Specificity of Notch3 immunoreactivity was confirmed by the control step of omitting each primary antibody (Figure $1 \mathrm{~m}$ ) and replacing it with an isotype-matched antibody (Figure 1r). 
Anti-Notch3 antibodies raised against extracellular epitopes display an intense and granular immunoreactivity in CADASIL brains. Using the 1E4 anti-Notch3 monoclonal antibody raised against an extracellular epitope, we found a prominent increase and a granular appearance of Notch3 immunoreactivity in the vascular smooth muscle cells in CADASIL brains $(n=8)$ (Figure $2, b, d, f$, and $h$ ) that contrasted with the weak and homogeneous staining in control brains $(n=5)$ (Figure 2, a, c, e, and g). Notch3 staining was specific based on 2 things: the absence of staining of vascular smooth muscle cells in the absence of primary antibody (Figure $2 i)$ or in the presence of an isotype-matched antibody (Figure 2j); and the similarity of results obtained with 2E11, another anti-Notch3 antibody raised against an extracellular epitope (Figure 21). This intense Notch3 immunoreactivity was observed in all vessels, including arteries, veins, and capillaries throughout CADASIL brain parenchyma, and was detected both in vascular smooth muscle cells (Figure 2, b, d, and f) and pericytes (Figure $2 \mathrm{~h}$ ), leading to a stippled decoration of the brain parenchyma. These data strongly suggested an abnormal accumulation of the Notch3 receptor.

In contrast, using the 6A10 anti-Notch 3 monoclonal antibody raised against an intracellular epitope, we found only weak immunoreactivity in the vascular smooth muscle cells in CADASIL brains, equivalent to that observed in control brains (data not shown).

Wild-type Notch3 is cleaved, producing 210-kDa and 97$k D$ a fragments. Discrepancy between immunostaining patterns obtained with the anti-intracellular and antiextracellular Notch3 antibodies, and the possibility that Notch3 undergoes a proteolytic cleavage similar to that experienced by the other Notch receptors raised the question of the nature of the Notch3 immunoreactive material that accumulates in CADASIL brains. As a first step, we investigated the processing of the wildtype Notch3 receptor.

$293 \mathrm{~T}$ cells transfected with the full-length wild-type Notch3 cDNA expressed the full-length Notch3 precursor ( 280 kDa) detected both by 5 G7 (anti-intracellular) and 5E1 (anti-extracellular) anti-Notch3 anti-

\section{Figure 3}

Proteolytic processing of wild-type Notch3. (a) Diagram of the Notch3 protein. Bars below the diagram indicate the various regions used as antigens to generate Notch3 antibodies (monoclonal antibodies 5E1, 11A1, and 5G7; polyclonal antibodies BC2 and BC4). TM, transmembrane domain. (b) Western blot analysis of transfected 293T cells and human control arterial tissue. Extracts were prepared from 293T cells transfected with human Notch1 (N1), Notch2 (N2), Notch3 (N3), or pSG5 vector (V). Fragment of a renal artery from a control individual was homogenized and then centrifuged at $16,000 \mathrm{~g}$. The resulting pellet and supernatant were adjusted to $1 \times$ SDS-Laemmli buffer. Thirteen micrograms of transfected 293T cells and approximately $100 \mu \mathrm{g}$ of pellet and supernatant (Sup) from the control artery were run on a $6 \%$ SDS-PAGE gel and incubated after transfer with 5E1 (left) and 5G7 (right). Positions of the 280-kDa full-length Notch3 (large black arrow) and the 210-kDa and 97$\mathrm{kDa}$ processing products are indicated (open arrowhead and small arrow, respectively). Notice the weak expression level of Notch3 in arterial tissue, which required more than 1 hour of exposure as opposed to a few seconds for transfected cells. (c) Notch3 210-kDa and 97$\mathrm{kDa}$ processing products are associated. Extracts from 293T cells transfected with Notch3 cDNA (N3) or vector alone (V) were immunoprecipitated with $\mathrm{BC} 2$ and $\mathrm{BC} 4$ polyclonal antibodies and with preimmune serum (PPI). Precipitated proteins were resolved by SDS-PAGE and immunoblotted with 5E1 and 5G7 antibodies. IP, immunoprecipitation. Migration of molecular-weight markers is shown to the left of each panel.
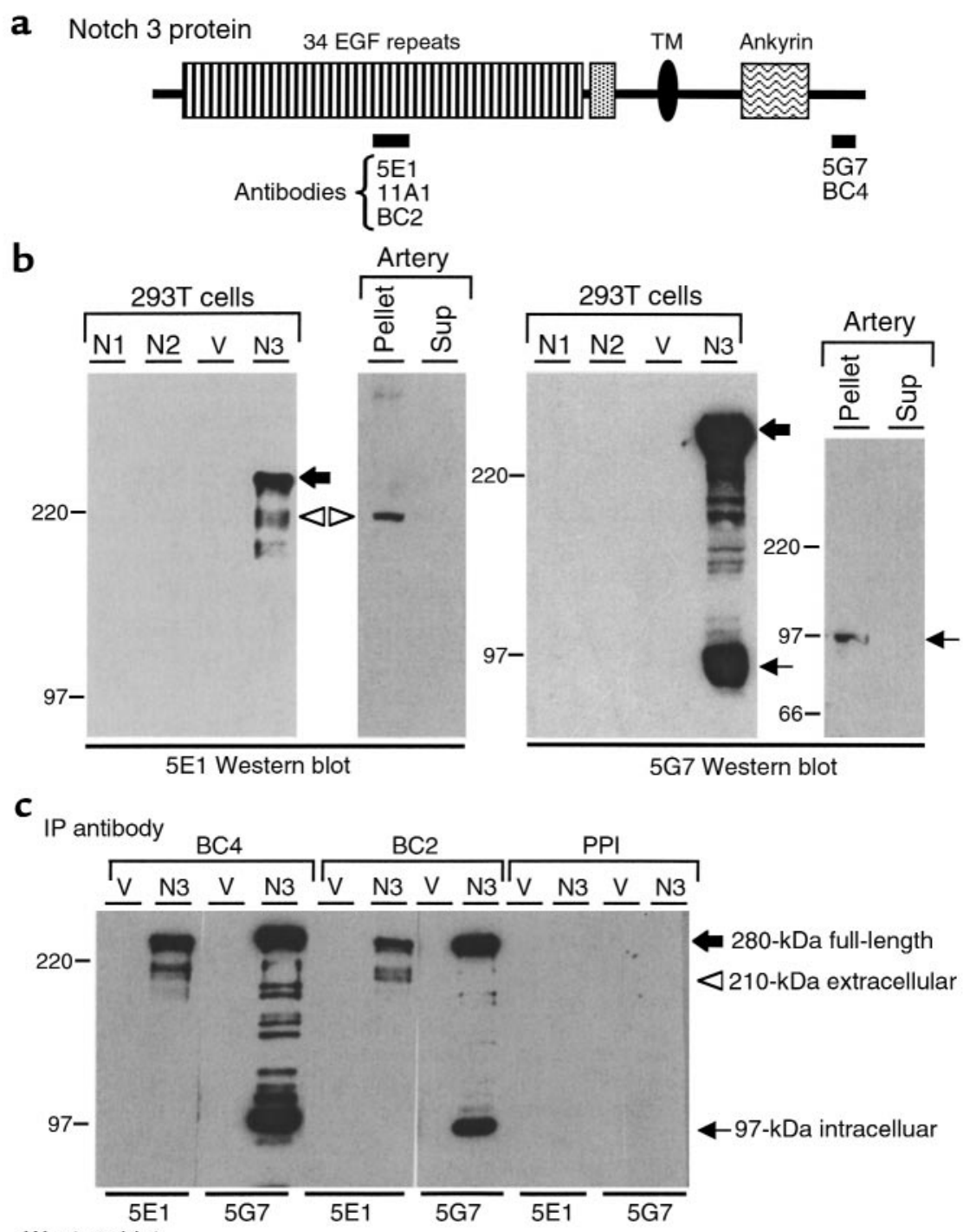

Western blot 


\section{Figure 4}

Selective accumulation of the 210-kDa cleavage product in CADASIL patients. ( $\mathbf{a}$ and $\mathbf{b}$ ) Western blot analysis of brain extracts from CADASIL and control individuals with antibodies raised against Notch3 extracellular domain. (a) Brain fragments were homogenized and centrifuged at $16,000 \mathrm{~g}$; the resulting pellet and supernatant were adjusted to $1 \times$ SDS-Laemmli buffer. Approximately $100 \mu \mathrm{g}$ of extracts were loaded per lane on a 6\% SDS-PAGE gel, and were immunoblotted with the $5 \mathrm{E} 1$ antibody. Blots were stained with Ponceau $\mathrm{S}$ to confirm that equal amounts of proteins were loaded. Left panel, brain extracts (supernatant and pellet) from CADASIL patient 1 and control individuals 2 and 5. Middle panel, brain extract (pellet) from CADASIL patient 1 and extract from 293T cells transfected with Notch3 cDNA (N3). Right panel, brain extracts (pellet) from CADASIL patients 1, 8, and 9. Position of the 210-kDa Notch3 protein (open arrowhead) detected in CADASIL brain extracts is indicated. The asterisk marks a band of unknown significance (cross-reacting material or, most likely, post-lysis degradation product). (b) Brain extracts from CADASIL patient 1 (pellet) and control individual 2 (pellet), and extracts from 293T cells transfected with Notch3 cDNA (N3) were run on a $6 \%$ SDS-PAGE gel and immunoblotted with the $11 \mathrm{~A} 1$ antibody (left panel) or without primary antibody (-) (right panel). (c) The $97-\mathrm{kDa}$ Notch3 protein is not detected in either CADASIL or control brains. Whole lysates were prepared from brains of CADASIL patient 1 and control individual 5 , and from a renal artery of a control subject. Approximately $100 \mu \mathrm{g}$ of each extract was loaded on a $6 \%$ SDS-PAGE gel and immunoblotted with the $5 \mathrm{G} 7$ antibody (bottom) and the 5E1 antibody (top). Positions of the $210-\mathrm{kDa}$ and the $97-k D a$ processing products are indicated (open arrowhead and small arrow, respectively). (d) Western blot analysis of extracts from CADASIL and control arterial tissues. Whole lysates were prepared from mesenteric arteries of CADASIL patient 1 and a renal artery of a control subject. Extracts were resolved on a 6\% SDS-PAGE gel and immunoblotted with the 5G7 antibody (right) and the 5E1 antibody (left). The asterisk marks a band of unknown significance (cross-reacting material or, most likely, a post-lysis degradation product). Whole lysates were used in experiments shown in $\mathbf{c}$ and $\mathbf{d}$ to avoid missing any soluble Notch3 intracellular fragment. (e) Western blot analysis of extracts from CADASIL and control brains and from control arterial tissue under reducing and nonreducing conditions. Extracts from CADASIL and control brains and from a control artery were solubilized in SDS-Laemmli buffer with or without $\beta M E$ and were resolved on a $6 \%$ SDS-PAGE gel. Both stacking (bracket) and separating gels were immunoblotted with the 5E1 antibody. Under reducing conditions $(\beta M E+)$, the $210-\mathrm{kDa}$ Notch3 protein is detected in both control artery and CADASIL brain (open arrowhead). Under nonreducing conditions ( $\beta \mathrm{ME}-$ ), no band is detected in the CADASIL brain; a protein of approximately $280 \mathrm{kDa}$ (large open arrow) is detected in the control artery. This protein probably corresponds to the associated extracellular and intracellular domains. Cross-reacting material is caught at the transition between the stacking and separating gels.

bodies, as well as proteins of approximately $97 \mathrm{kDa}$ and $210 \mathrm{kDa}$ detected by $5 \mathrm{G} 7$ and 5E1 antibodies, respectively (Figure 3, a and b). Coimmunoprecipitation experiments provided evidence that the $97-\mathrm{kDa}$ and the 210-kDa cleavage products were associated (Figure 3c).

In control tissues, Notch3 was detected in extracts from arteries, including leptomeningeal, large cerebral, and extracerebral arteries, but not from brain parenchyma (Figure $3 \mathrm{~b}$ and data not shown). The latter finding is probably explained by the weak expression level of this receptor and by the fact that smooth

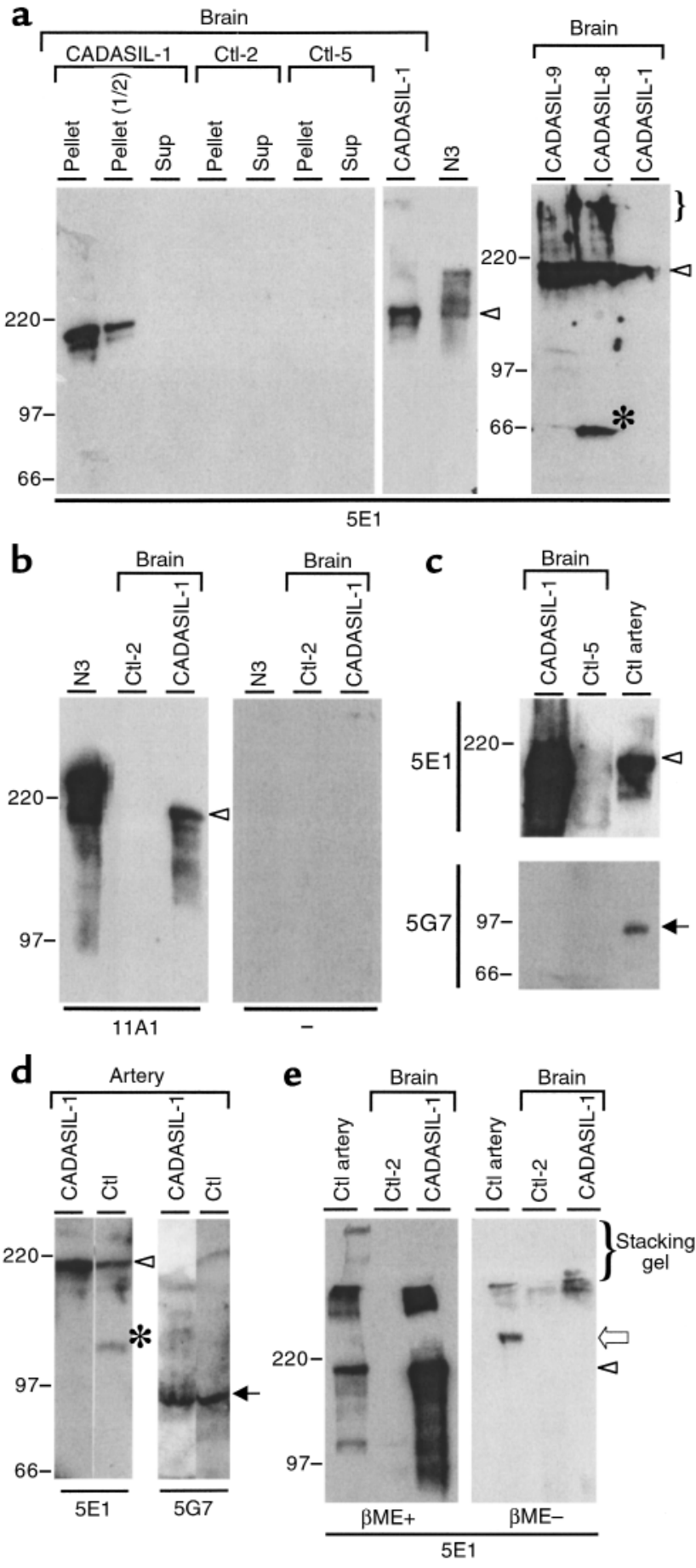

muscle cells and pericytes represent a minor cellular population within the brain parenchyma. Arteries expressed the $210-\mathrm{kDa}$ and the $97-\mathrm{kDa}$ fragments, but not the $280-\mathrm{kDa}$ full-length protein (Figure $3 \mathrm{~b}$ ). These data strongly suggested that Notch3 undergoes a proteolytic cleavage identical to that of the Notch 1 and Notch2 receptors.

Dramatic and selective accumulation of the 210-kDa Notch3 cleavage product in CADASIL patients. To further confirm Notch 3 accumulation in CADASIL brains, and to investigate the nature of the Notch3 immunoreactive mate- 
rial, we performed Western blot analysis on lysates from CADASIL tissues. In CADASIL brains $(n=3)$, the 5E1 and 11A1 anti-extracellular antibodies detected a prominent $210-\mathrm{kDa}$ protein; under the same experimental conditions using control brains $(n=2)$, Notch 3 protein was not detected (Figure 4, a and b). The size of the Notch3 immunoreactive material that accumulated in CADASIL brains was identical to the $210-\mathrm{kDa}$ Notch3 cleavage product, including the extracellular domain detected in Notch3-transfected cells and in control arterial tissue (Figure 4, a-c).

By contrast, both the $5 \mathrm{G} 7$ monoclonal antibody and the BC4 polyclonal anti-intracellular antibody failed to detect any signal in CADASIL brains, even though the $97-\mathrm{kDa}$ fragment was detected successfully on the same Western blot in a control artery (Figure $4 \mathrm{c}$ and not shown). When using arterial tissues (considerably enriched in vascular smooth muscle cells) from either a control individual or a CADASIL patient, both $210-\mathrm{kDa}$ and $97-\mathrm{kDa}$ Notch3 cleavage products were detected. Comparative analysis of the relative amounts of the $210-\mathrm{kDa}$ and $97-\mathrm{kDa}$ proteins provided strong evidence of the accumulation of the 210$\mathrm{kDa}$ fragment in the CADASIL patient. By contrast, an almost equivalent amount of the $97-\mathrm{kDa}$ fragment was observed in both the control subject and a CADASIL patient. This $97-\mathrm{kDa}$ fragment was of similar size in control and CADASIL arteries (Figure 4d).

The mutant Notch3 ectodomain probably undergoes an improper oligomerization. To investigate whether the odd number of cysteines in mutant Notch3 might favor its improper oligomerization and contribute to its accumulation, we performed Western blot analysis on lysates from CADASIL brains under nonreducing conditions with the 5E1 antibody. No band was detected in the CADASIL brain (Figure $4 \mathrm{e}, \beta \mathrm{ME}-$ ) under these conditions, even though a prominent quantity of Notch 3 protein was detected under reducing conditions (Figure $4 \mathrm{e}, \beta \mathrm{ME}+$ ). These results strongly suggested that in the absence of reducing agents, it is likely that mutant Notch 3 consists of large complexes that were unable to enter the SDS-PAGE gel. Under nonreducing conditions, the artery from a control individual, used as a positive control, expressed a band of approximately $280 \mathrm{kDa}$ that may correspond to the tightly associated extracellular and intracellular cleavage products (Figure $4 \mathrm{e}, \beta \mathrm{ME}+$ ), as reported previously for Notch1 (17). Equivalent proteolytic processing and subcellular distribution of wild-type and mutated Notch 3 proteins in 293 T cells transfected with the wild-type and mutant Notch 3 cDNAs. To further explore the mechanisms by which the Notch3 ectodomain abnor- mally accumulated, we examined the subcellular distribution of wild -type and mutant Notch $3\left(\mathrm{R}_{90} \mathrm{C}\right.$ and $\mathrm{C}_{212} \mathrm{~S}$ ) in $293 \mathrm{~T}$ cells transfected with the wild-type or the mutant Notch3 cDNAs. Wild-type Notch 3 protein was detected within the endoplasmic reticulum, the Golgi apparatus, and at the cell surface by immunofluorescence analysis (not shown). The $97-\mathrm{kDa}$ and the 210-kDa cleavage products of the wild-type Notch3 were the major species detected at the cell surface using biotin labeling of surface proteins (Figure 5 and not shown). We found that proteolytic processing and subcellular distribution of mutant Notch3 were both equivalent to those of the wild-type Notch3 (Figure 5 and not shown). Furthermore, we did not obtain evidence of an abnormal accumulation of the $210-\mathrm{kDa}$ cleavage product in $293 \mathrm{~T}$ cells transfected with the mutant Notch 3 cDNAs.

Notch 3 accumulates at the cytoplasmic membrane of vascular smooth muscle cells in close vicinity to the granular osmiophilic deposits. To search further for the subcellular compartment where Notch3 accumulated and to investigate whether Notch3 accumulation might account for the granular osmiophilic deposits, we performed immunoelectron microscopy analysis on sections from a CADASIL brain. Notch3 immunolabeling was detected at the cytoplasmic membrane of vascular smooth muscle cells (Figure 6). It was highly restricted to small areas located close to the granular osmiophilic deposits, which themselves were not labeled by the antiNotch3 antibody .

\section{Discussion}

Notch3 expression is restricted to vascular smooth muscle cells in human adult tissues. The restricted expression pattern

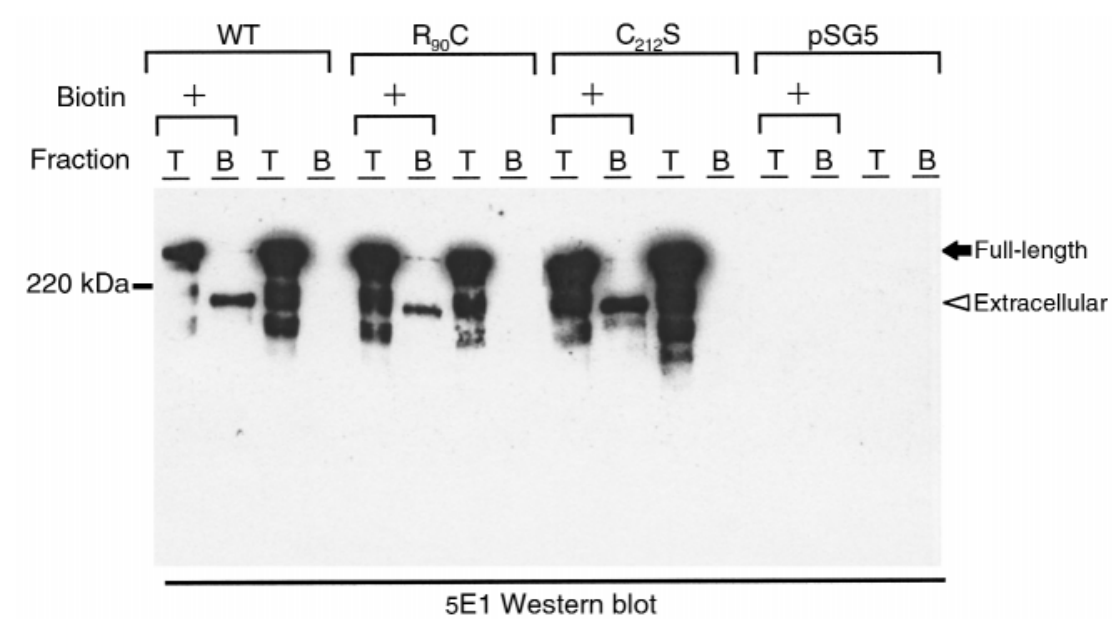

\section{Figure 5}

Wild-type and mutant Notch3 proteins expressed at the cell surface of transfected 293T cells are cleaved. 293T cells transfected with wild-type Notch3 (WT), mutant Notch3 ( $\mathrm{R}_{90} \mathrm{C}$ and $\mathrm{C}_{212} \mathrm{~S}$ ), and vector alone (pSG5) were incubated with sulfo-NHS-biotin (+) or were mock treated. Cells were lysed in RIPA buffer, and extracts were loaded on a 6\% SDS-PAGE gel either directly ( $T$ fraction, 15\% of the extract) or after incubation on streptavidin-agarose beads ( $\mathrm{B}$ fraction, $85 \%$ of the extract). Extracts were then immunoblotted with the $5 \mathrm{E} 1$ antibody. Positions of the 280-kDa full-length Notch3 extracellular domain (black arrow) and the 210-kDa Notch3 extracellular domain (arrowhead) are indicated. 


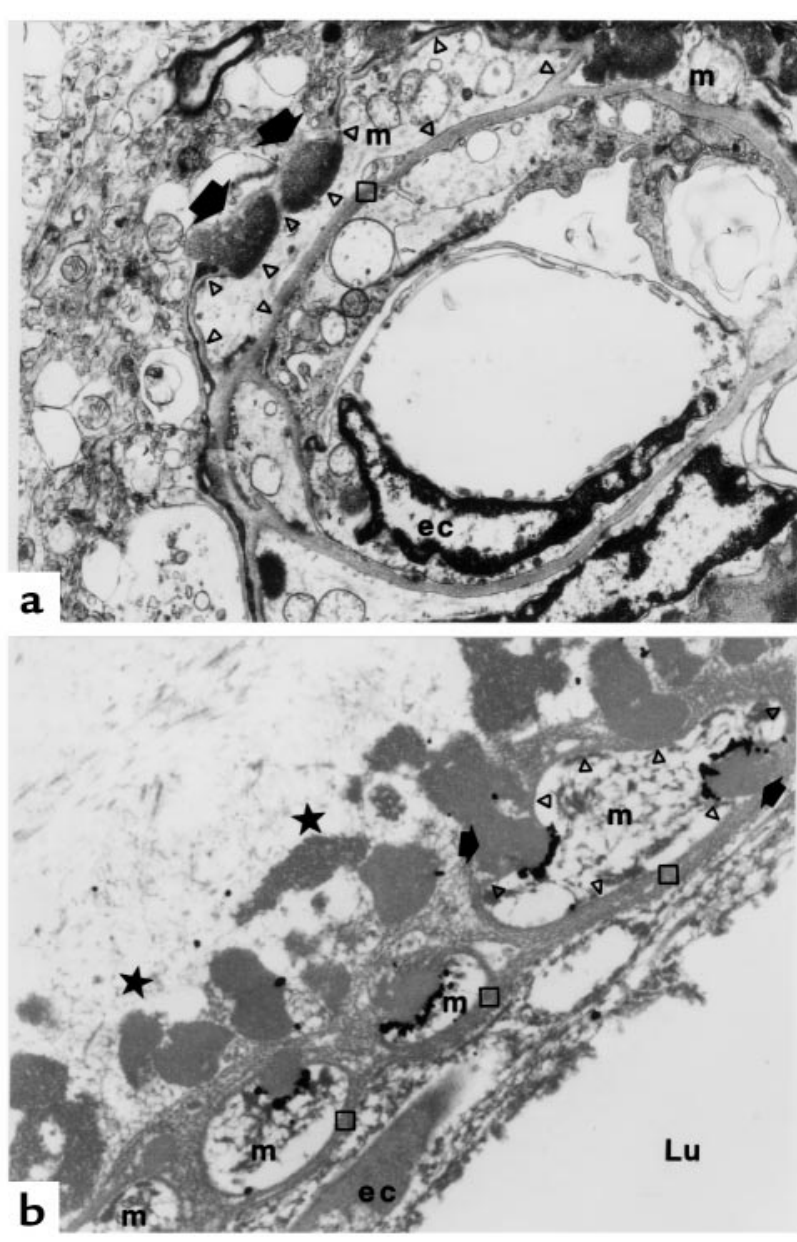

Figure 6

Notch3 immunogold labeling is highly clustered at the cell surface of smooth muscle cells. (a) Vessel within the frontal lobe of CADASIL patient 1 , processed for electron microscopy using standard procedure. Outline of a smooth muscle cell $(\mathrm{m})$ is indicated by open small arrows. Granular osmiophilic deposits (large arrows) are observed within the basal lamina (square), in close contact with the cytoplasmic membrane of this smooth muscle cell. $\times 13,000$. (b) Vessel within the occipital lobe from CADASIL patient 1, processed for immunoelectron microscopy with the 1E4 antibody. Numerous granular osmiophilic deposits (large arrows) are observed within the basal lamina (square). These are nested within invaginations of the smooth muscle cells $(\mathrm{m})$, or are spread far away within the vessel wall (stars). Notch3 immunolabeling, which appears as black dots due to silver enhancement, is highly clustered at the cell membrane of smooth muscle cells (open small arrows) closely arranged around the deposits, which are not labeled. $\times 20,000$. Ultrathin sections stained with uranyl acetate and lead citrate. ec, endothelial cell; Lu, lumen.

we observed in human adult tissues was quite unexpected because it is in sharp contrast with the broad pattern reported in rodents during the early stages of development (12-14). Nevertheless, when we reinvestigated Notch3 expression in late-stage murine embryos (embryonic day 16.5), we found a similar profile that was highly restricted to the vasculature (A. Joutel, unpublished results). The expression pattern of Notch3 suggests some hypotheses regarding its putative role in adult tissues. Other Notch proteins have been shown to block cell differentiation or to otherwise control cell fate. Vascular smooth muscle cells, which are mature but non-terminally differentiated cells, exhibit a remarkable phenotypic plasticity in response to a variety of stimuli (18). One can speculate that the Notch3 signaling pathway may be involved in the phenotypic modulation of these cells and determining whether they retain a differentiated contractile phenotype or adopt an undifferentiated proliferative phenotype.

Dramatic accumulation of Notch3 in the cerebrovasculature of CADASIL patients. Our results provide convincing evidence of prominent accumulation, in the cerebrovasculature of CADASIL patients, of the $210-\mathrm{kDa}$ proteolytic cleavage product that corresponds to the ectodomain of the Notch 3 receptor. In addition, we established that this accumulation takes place at the cytoplasmic membrane of vascular smooth muscle cells and pericytes. Two possibilities may account for this finding: increased production of Notch3, or impaired clearance of the Notch3 receptor from the cell surface. Because we found that relative amounts of Notch3 mRNA were essentially identical in both CADASIL and control individuals (data not shown), the first possibility seems very unlikely. Improper oligomerization of the mutant Notch3 ectodomain, strongly suggested by our data, probably contributes to its impaired clearance.

Unexpectedly, immunoelectron microscopy revealed that Notch3 accumulation did not take place within the characteristic granular osmiophilic material, but occurred in close vicinity to it. Whether and how the Notch 3 ectodomain and the accumulation of this material are mechanistically linked remains to be investigated.

The next important challenge will be to determine whether CADASIL mutations lead to inhibition - or alternatively, activation - of the Notch3 signaling pathway. Proteolytic cleavage and nuclear translocation of the intracellular domain of Notch receptors have recently been linked to receptor signaling (19-21). In CADASIL brains, Notch3 intracellular domain was not detected in the nucleus. Immunoblot analysis of CADASIL arterial tissue provided no evidence of an additional proteolytic cleavage of the 97$\mathrm{kDa}$ protein. However, no definite conclusion can presently be drawn from these negative results, because activation of the Notch signaling pathway has been reported to occur with a very small amount (below the level of detection) of nuclear Notch intracellular domain (19). Further work such as expression analysis of downstream target genes and in vitro experiments should help in addressing this important issue. Another important issue will be to determine whether Notch3 accumulation occurs in a liganddependent or ligand-independent context. This will require, as a first step, identification of Notch3 ligands that are so far unknown.

Implications for CADASIL diagnosis. Detection of granular osmiophilic material typical of CADASIL requires ultrastructural analysis, which is an intensive 
and time-consuming procedure. Furthermore, mutational scanning of the Notch3 gene is hampered by the large number of exons requiring analysis (9). In this study, we established that CADASIL mutations cause a pronounced accumulation of Notch3, leading to a characteristic immunostaining pattern in CADASIL tissues. Recent results from our lab indicate that Notch3 accumulation is also detected in many other parenchymal tissues, including muscle and skin obtained from biopsy (A. Joutel et al., unpublished observations). Therefore, we propose that Notch3 antibodies could be useful for diagnostic CADASIL screening procedures.

Our results indicate that vascular smooth muscle cells are the primary target in the cascade of events leading from Notch3 mutations to the CADASIL arteriopathy. Determining the role of Notch3 should ultimately allow elucidation of whether and how Notch3 mutations cause vascular smooth muscle cell alterations.

\section{Acknowledgments}

The authors thank M.G. Bousser (Hôpital Lariboisière, Paris, France); B. Dubois, J.J. Hauw, H. Beaufils, and V. Sazdowitch (Centre Hospitaler Universitaire [CHU], Pitié Salpêtrière, Paris, France); D. Leys and M.M. Ruchoux (CHU, Lille, France); M. Baudrimont (Hôpital St Antoine, Paris, France); F. Berthelet (Campus Notre-Dame, Montréal, Quebec, Canada); P. Davous (Centre Hospitaler Victor Dupuy, Argenteuil, France); C. Fallet-Bianco (Hôpital Ste. Anne, Paris, France); P. Burkhardt and G.P. Pizzolato (Hôpital Universitaire, Genève, Geneva, Switzerland); M.C. Gubbler (CHU Necker Enfants-Malades, Paris, France); J. Mikol (Hôpital Lariboisière, Paris, France); and G. Tietjen (Henry Ford Hospital, Detroit, Michigan, USA) for referring patients and making autopsy tissues available. We thank S. Artavanis-Tsakonas (Massachusetts General Hospital Cancer Center, Harvard Medical School, Charlestown, Massachusetts, USA) for the full-length Notch1 and Notch2 plasmids and monoclonal antibodies against Notch1 (bTAN20) and Notch2 (bHn6), and E. McIntyre (Hôpital Necker, Paris, France) for providing Porphobilinogen deaminase primers. We are indebted to J.M. Gasc (U 36, Collège de France, Paris, France) for teaching us the in situ hybridization protocol, and to C. Berthelin for technical assistance with electron microscopy.
Support for this work was provided by grants from INSERM, from the Association Française contre les Myopathies, and from bioMérieux.

1. Joutel, A., et al. 1996. Notch3 mutations in CADASIL, an hereditary adultonset condition causing stroke and dementia. Nature. 383:707-710.

2. Tournier-Lasserve, E., Iba-Zizen, M.T., Romero, N., and Bousser, M.G. 1991. Autosomal dominant syndrome with stroke-like episodes and leukoencephalopathy. Stroke. 22:1297-1302.

3. Tournier-Lasserve, E., et al. 1993. Cerebral autosomal dominant arteriopathy with subcortical infarcts and leukoencephalopathy maps to chromosome 19q12. Nat. Genet. 3:256-259.

4. Chabriat, H., et al. 1995. Clinical spectrum of CADASIL: a study of 7 families. Lancet. 346:934-939.

5. Baudrimont, M., Dubas, F., Joutel, A., Tournier-Lasserve, E., and Bousser, M.G. 1993. Autosomal dominant leukoencephalopathy and subcortical ischemic stroke. A clinicopathological study. Stroke. 24:122-125.

6. Ruchoux, M.M., et al. 1995. Systematic vascular smooth muscle cell impairment in cerebral autosomal dominant arteriopathy with subcortical infarcts and leukoencephalopathy. Acta Neuropathol. (Berl.). 89:500-512.

7. Ruchoux, M.M., and Maurage, C.A. 1997. CADASIL: cerebral autosomal dominant arteriopathy with subcortical infarcts and leukoencephalopathy. J. Neuropathol. Exp. Neurol. 56:947-964.

8. Artavanis-Tsakonas, S., Rand, M.D., and Lake, R.J. 1999. Notch signaling: cell fate control and signal integration in development. Science. 284:770-776.

9. Joutel, A., et al. 1997. Strong clustering and stereotyped nature of Notch3 mutations in CADASIL patients. Lancet. 350:1511-1515.

10. Blaumueller, C.M., Qi, H., Zagouras, P., and Artavanis-Tsakonas, S. 1997. Extracellular cleavage of Notch leads to a heterodimeric receptor on the plasma membrane. Cell. 90:281-291.

11. Logeat, F., et al. 1998. The Notch1 receptor is cleaved constitutively by a furin-like convertase. Proc. Natl. Acad. Sci. USA. 95:8108-8112.

12. Lardelli, M., Dahlstrand, J., and Lendahl, U. 1994. The novel Notch homologue mouse Notch3 lacks specific epidermal growth factor-repeats and is expressed in proliferating neuroepithelium. Mech. Dev. 46:123-136.

13. Williams, R., Lendahl, U., and Lardelli, M. 1995. Complementary and combinatorial patterns of Notch genes family expression during early mouse development. Mech. Dev. 53:357-368.

14. Lindsell, C.E., Boulter, J., diSibio, G., Gossler, A., and Weinmaster, G. 1996. Expression patterns of Jagged1, Delta1, Notch1, Notch2, and Notch3 genes identify ligand-receptor pairs that may function in neural development. Mol. Cell. Neurosci. 8:14-27.

15. Sibony, M., Commo, F., Callard, P., and Gasc, J.M. 1995. Enhancement of mRNA in situ hybridization signal by microwave heating. Lab. Invest. 73:586-591.

16. Caron, A., Gohel, C., Mollaret, K., Morello, R., and Chapon, F. 1999. Study of some components of the cytoskeleton in muscular disorders with non specific cytoplasmic bodies. Acta Neuropathol. (Berl.). 97:267-274.

17. Ray, W.J., et al. 1999. Evidence for a physical interaction between the presenilin and Notch. Proc. Natl. Acad. Sci. USA. 96:3263-3268.

18. Owens, G.K. 1995. Regulation of differentiation of vascular smooth muscle cells. Physiol. Rev. 75:487-517.

19. Schroeter, E.H., Kisslinger, J.A., and Kopan, R. 1998. Notch-1 signalling required ligand-induced proteolytic release of intracellular domain. Nature. 393:382-386.

20. Struhl, G., and Adachi, A. 1998. Nuclear access and action of Notch in vivo. Cell. 93:649-660.

21. De Strooper, B., et al. 1999. A presenilin-1-dependent $\gamma$-secretase-like protease mediates release of Notch intracellular domain. Nature. 398:518-521. 